\title{
POISONING BY NITRIC OXID FUMES *
}

\author{
FRANCIS CARTER WOOD, M.D. \\ COLCMBLA LNIVERSITY, NEW YORK
}

This case of fatal poisoning by nitrogen tetroxid fumes is reported for its medicolegal interest and also because of the rarity of the condition. and a general lack of recognition of the pathological changes in the lungs of persons dying from the action of this very dangerous gas.

When nitric acid acts on certain metals, such as copper, silver, or cadmium, a gas is given off with the composition of NO or nitrogen dioxid. When this gas comes in contact with the air it absorbs oxygen, with the production of nitrogen tetroxid or $\mathrm{N}_{2} \mathrm{O}_{4}$. If either of these compounds of nitrogen and oxygen comes in contact with moisture, nitrogen dioxid forms nitric acid, while nitrogen tetroxid is slowly decomposed into nitric and nitrous acids. 'These are the decompositions which occur when brown fumes are given of by the action of nitric acid on the substances mentioned above.

When strong nitric acid acts on organic bodies it produces nitrogen trioxid. This immediately decomposes, however, into a mixture of nitrogen trioxid and nitrogen tetroxid. The nitrogen trioxid is continuously converted into nitrogen tetroxid by the action of the atmospheric air. Inhalation of these gaseous compounds occasionally occurs in laboratories or factories where considerable quantities of these fumes are formed, either during the course of some reaction or when a carboy of nitric acid is spilled.

'The inhalation of nitrogen tetroxid rapor, if not too concentrated, causes at first no symptoms, with the exception of a slight tendency to cough and an acid taste in the mouth. It has occasionally been observed that workmen have remained for some hours in a room in which nitric acid has been spilled without showing any evidences of injury, or that if on feeling uncomfortable they went into the open air, the symptoms have disappeared rapidly, only to recur in full force six to eight hours later. If the vapors are concentrated, the patient may suffer immediately from severe dyspnea, a feeling of pressure on the chest, coughing, faintness and cyanosis. Dyspnea and slight cyanosis are the frequent symptoms; the patient often on reaching the air also vomits any food that may be in the stomach and then feels perfectly well for a period of six or eight hours. At the end of this time, often without any inciting cause, some-

\footnotetext{
* Manuseript submitted for publication Aug. 31, 1912.
} 
times while the patient is quietly seated or asleep in bed, there is sudden attack of extreme dyspnea, with a sense of oppression in the chest, or a feeling of anxiety, so that the cases resemble acute attacks of asthma. Csually there is a good deal of thirst and a sense of suffocation. A cold sweat breaks out on the features, the eyes protrude, and the patient talks with difficulty. From time to time paroxysms of coughing occur, lasting from ten to fifteen minutes and terminating in vomiting. Cyanosis is regularly present. The mind is perfectly clear. The patient usually dies within forty-eight hours, though in some cases death has not occurred for five to eight days, or more rarely two to three weeks.

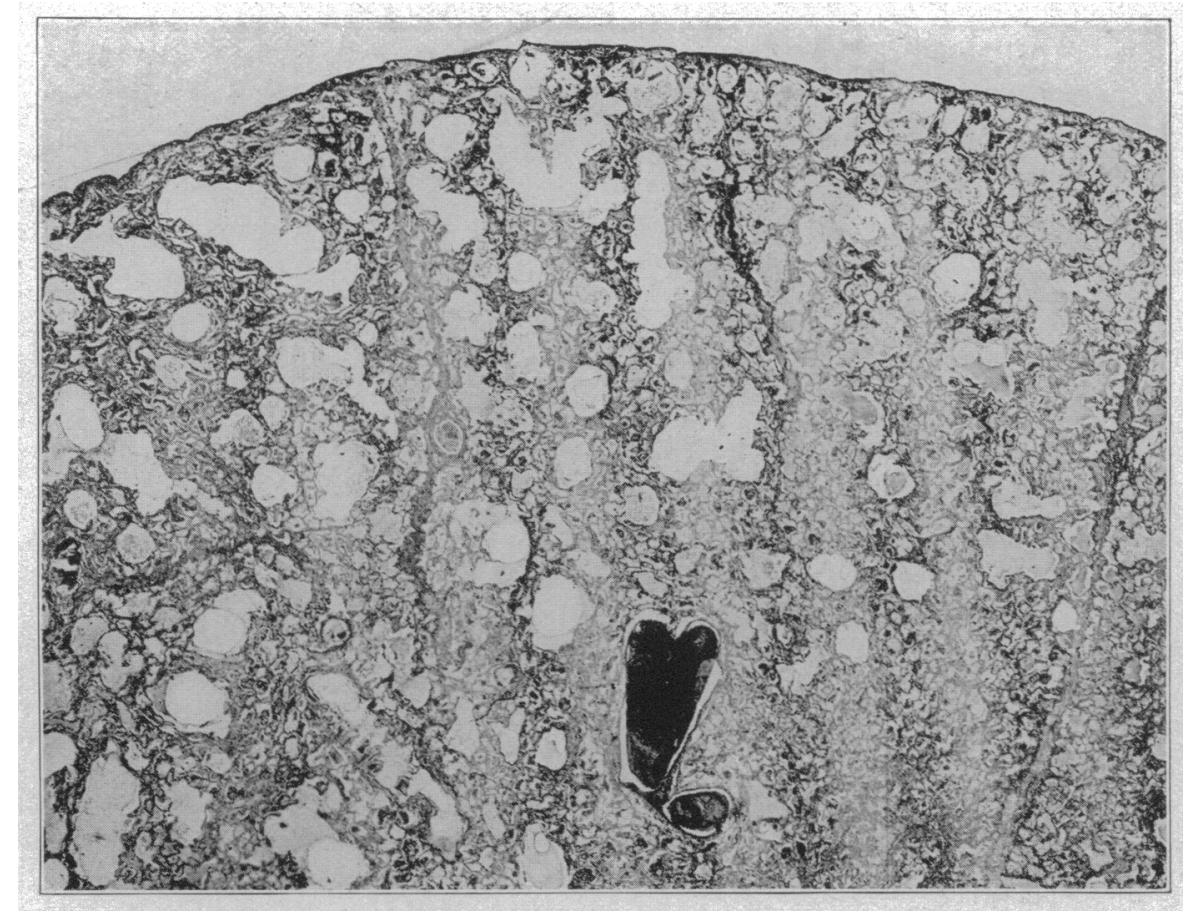

Fig. 1.-Case D. Low power of lung to show irregular distribution of pneltmonia ard emphysemat and thrombi in vessels. $\times 10$.

The blood is dark in color, but generally shows only oxyhemoglobin. ${ }^{1}$ The urine may show albumin and blood pigment (in one case, hematin), but not constantly. Death occurs in consequence of edema of the lungs, and is usually preceded by the expectoration of a good deal of foamy yellowish fluid and eridence of cardiac failure. In some cases severe diarrhea and collapse are observed, but this is not a frequent form of termination.

1. Czaplewski was able to demonstrate methenoglobin in only one out of twelve cases of severe poisoning. and this was not a fatal case. 
In patients who have inhaled small amounts of gas and have improred after the first attack of edema of the lungs, the disease may continue for a number of days with the clinical symptoms of acute bronchitis and eviteners in the chest of lobular or lobar pnetumonia. Usually there is extreme dyspnea. The sputum is tenacions, yelowish or brown. Tomiting nay be so extreme as to mask the pulmonary symptoms, though as a rule this is uncommon. Such cases may recover, but often show an increased liability to bronchitis or pneumonia for months afterward.

At autopsy the larynx, trachea and bromchi are congested and of a reddish or brownish color. If the patient dies shortly after exposure, the

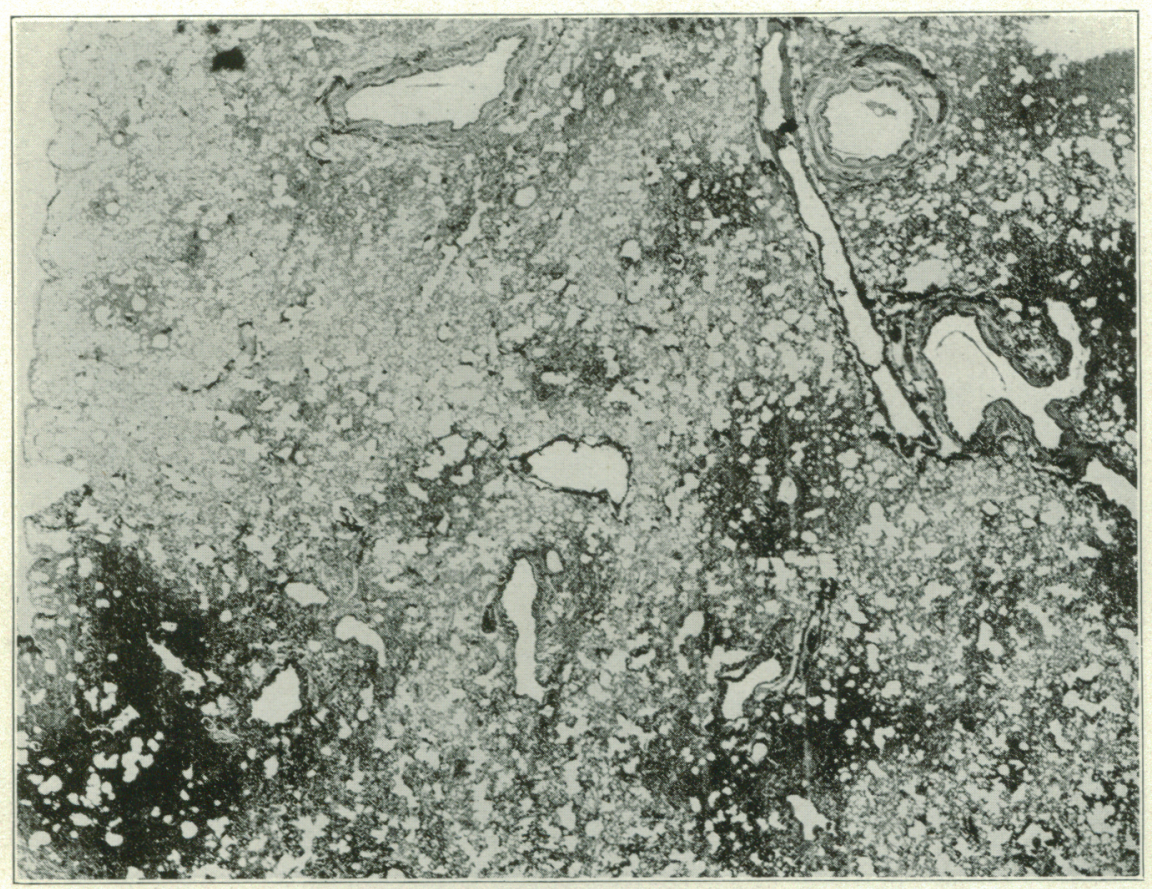

Fig. 2.-Dog 4. Lobular pneumonia with emphisema five days after inhalation of gas. Low power.

lung is edematous; in those living for several days, it is emphysematous, with, in addition, a moderate amount of pneumonic exudate. The vessels of the lung often contain thrombi. From the cut surface exudes a redish or brownish fluid. In the other organs ecchymoses are occasionally found. Focal necroses may occur in the liver. The meninges are often congested and there are occasionally punctate hemorrhages throughout the substance of the brain. The kidneys have in a few cases shown acute degeneration or acute nephritis; generally, however, they are not much altered. 
The number of published cases of death following the inhalation of rapors of nitrogen tetroxid is not very large; but owing to the greatly increased use of nitric acid in the arts, cases of such poisoning are likely to be more frequent in the future, and they may also assume a medicolegal importance in connection with accident insurance and employers' liability acts. On this account the following fatal case is reported, together with the results of animal experiments and a survey of the cases already published.

CASE REPORT

History.-The patient, D., in this instance, accidentally inhaled the fumes arising from a large vessel containing considerable quantities of nitric acid and a cadmium-silver alloy. The room in which the experiment was conducted was small, and the patient experienced some discomfort and a sensation of choking, and went into the open air. After a few minutes he vomited and then felt much better. There were no further symptoms until some six or eight hours later, when he was seized with intense dyspnea, and collapsed. Twenty-four hours later he entered the hospital, remaining there until his death seven days after the exposure.

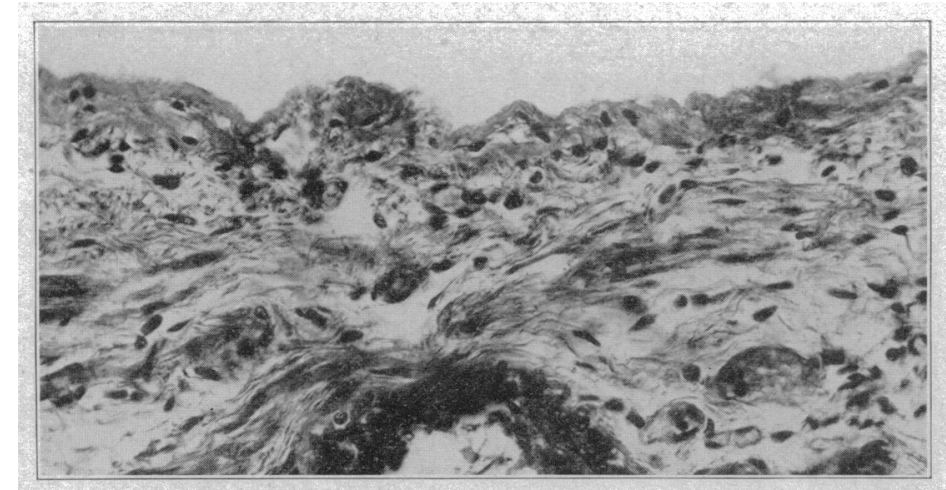

Fig. 3.-Case D. Medium sized bronchus showing edema of wall and loss of epithelium. $\times 250$.

On admission he complained chiefly of weakness, pain in the throat and chest, and intense dyspnea.

Examination.-Examination showed a well nourished man with slightly dilated heart, of rapid, feeble action, soft pulse. He was suffering at the time of the examination from very severe dyspnea, with extremely rapid, shallow respiration and marked cyanosis, Prostration was very extreme, but the patient's mind was clear. The pupils were equal and reacted. The lips and tongue were intensely cyanosed; the throat was congested. The lungs showed marked dulness at both bases posteriorly; bronchovesicular breathing, with slightly bronehial voice and scattered râles, most marked over the right base. The extremities were cold and cyanotic. The temperature ranged from $100^{\circ}$ to $102 \mathrm{~F}$; the pulse from about 100 to 140 ; respirations from 44 to 60 , during the patient's stay in the hospital. He was given oxygen inhalations, and blood was drawn for examination. It was very dark in color but when examined spectroseopically showed oxyhemoglobin only and no evidence of carbon monoxid ${ }^{2}$ or methemoglobin. Under the stimula-

2. Illuminating gas poisoning had been suspected. 
tion of the oxygen inhalations the patient got along fairly satisfactorily for several days. Examimation of the urine showed: Specific gravity, 1.026; albumin, 2 per cent. by volume; a few leukocytes, mucus, and red cells; no casts. Repeated examinations gave the same findings, except that three days before death the urine contained a trace of albumin only and a few hyaline casts. The day before the patient died there was 5 per cent. of albumin by volume, with a few hyaline and granular casts.

During the last few days the patient's respiration was very labored; he was restless and complained of headache and nausea, and was able to sleep only a few hours during the right. The day before be diel he became very restless and was irrational; the pulse was very feeble and irregular, and breathing was increasingly difficult. While there was at times an annoying cough, this was never a prominent symptom. The only alteration in the physical signs noted

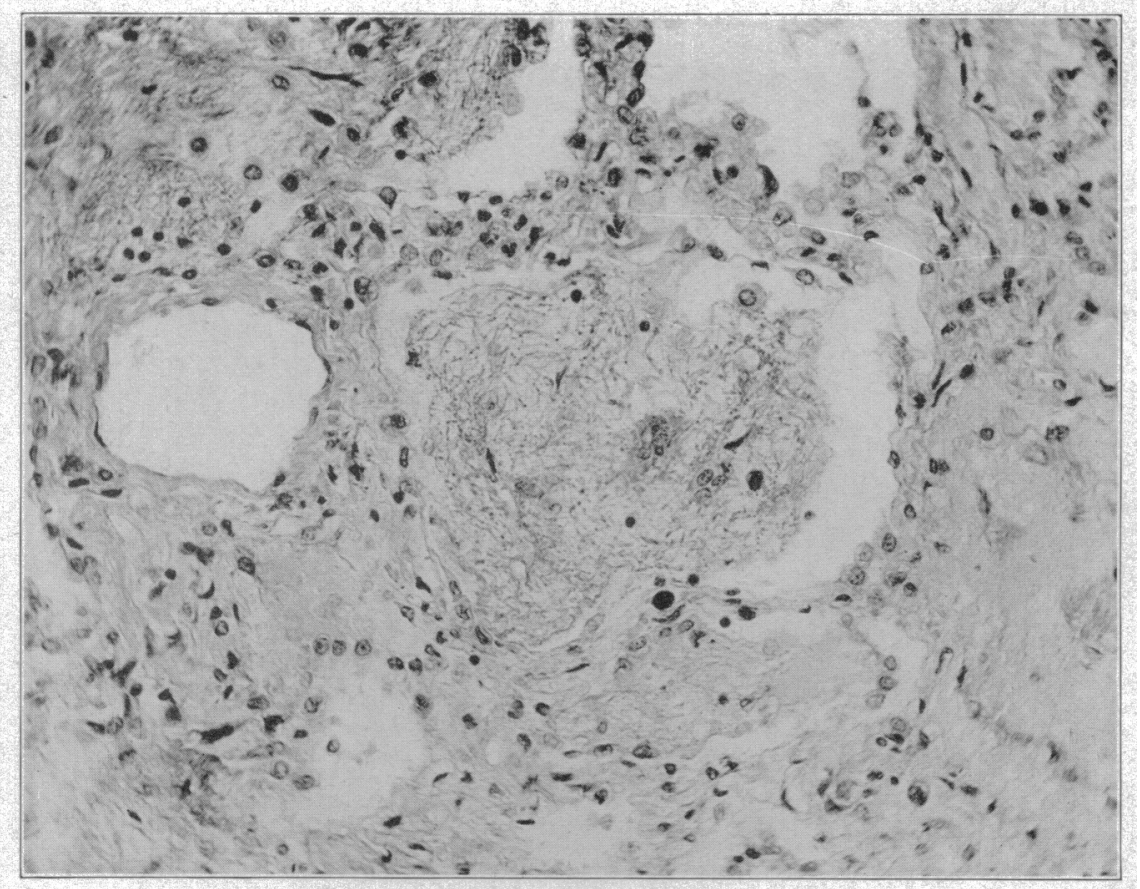

Fig. 4.-Case D. Fibrinous and hyaline exudate. $\times 250$.

was an increase in the area of dulness in the lungs and evidences of congestion and edema of the upper lobes.

The red blood-cell count was 5,400,000 with normal morpho!ogy; the hemoglobin was 90 per cent. The white blood-cell count was 17,000 ; polynuclears 68 per cent., Jymphocytes, 30 per cent., basophils, 2 per cent.

Necropsy.-At autopsy, which was done after embalming with a fluid containing formaldehyd, the important gross lesions found were as follows:

1. An irregular cavity with sharply defined walls in the corpus striatum on each side of the brain, containing a clear, colorless fluid.

2. A moderately dense lobular pneumonia in the lower and posterior portion of the lungs on both sides.

The liver and kidneys showed nothing abnormal. The heart was dilated and looked pale and fatty. 
Microscopical Examination.-The microscopical examination of the tissues was not at all interfered with by the previous embalming, the organs being in excellent condition and thoroughly hardened.

The lesion in the brain was of especial interest, inasmuch as the patient had had a severe accident about a year before his death. Yet the examination of the tissues involved did not permit of a connection between this lesion and the accident for the following reasons: First, the cavity contained clear watery fluid, which was not blood stained. Such a fluid would be seen only in either a congenital or a parasitic cyst of the brain, and such a lesion would not in all probability be symmetrical. Second, the walls of the cavity were perfectly sharp. Microseopica! sections showed that the individual brain cells along the walls were perfectly preserved, and that small capillary vessels had been torn across, the ends still remaining open. There was not the sliyhtest evidence of an inflammatory reaction or the formation of a membrane. It is probable, therefore, that this tear was formed post mortem by the.injection at high pressure of the

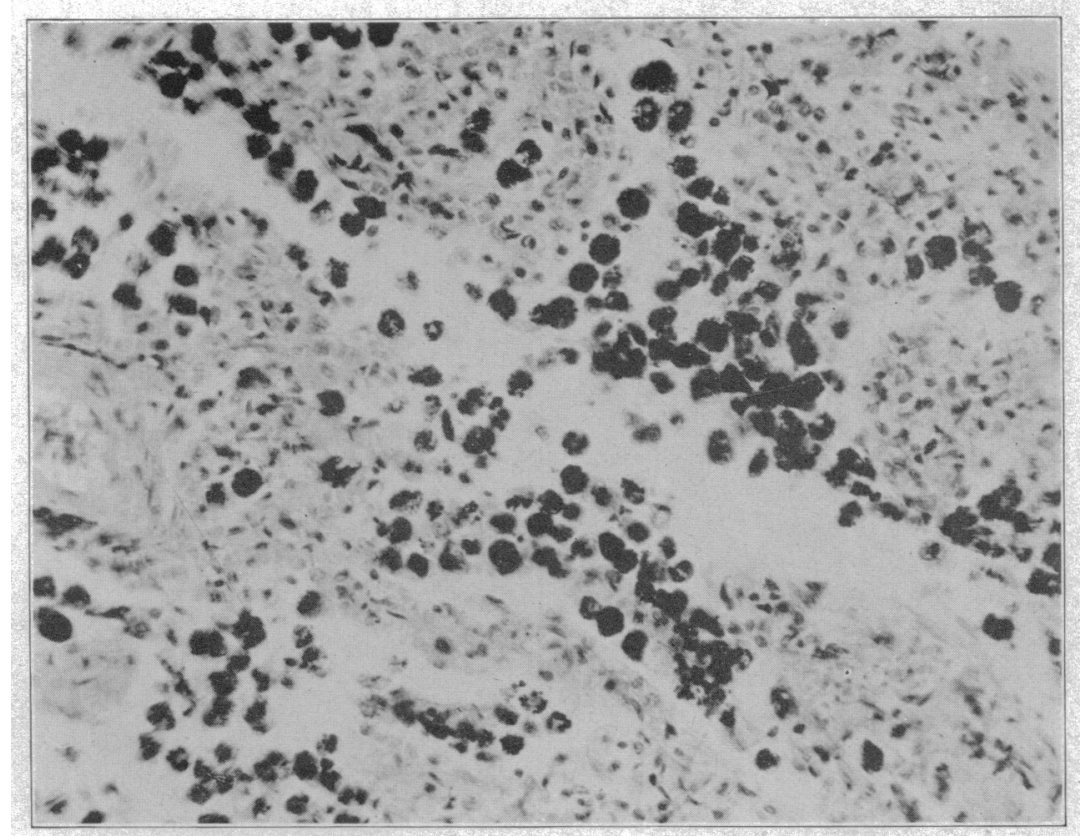

Fig. 5.-Case D. Areas containing chiefly pigmented cells, $\times 250$.

embalming fluid. That this is possible was proved by some experiments on human cadavers in which similar artefacts were inciuced. The vessels may have been weakened by the action of the poison, especially as Tomellini ${ }^{3}$ has shown that in acute nitrite poisoning small hemorrhages can be found in the organs, usually confined, lowever, to the stomach, intestine and liver. As stated above, small quantities of nitrous acid may be formed when nitroger tetroxid comes in contact with moisture. Such nitrous acid would naturally combine with the free alkali in the tissues and blood and circulate as sodium nitrite. This might be the cause also of the very soft and rapid pulse occasionally seen in these cases of poisoning, and suggests an explanation for the very dark color of the blood noted in almost all cases of this form of intoxication, it being well known that nitrites

3. Tomellini: Beitr. z. path. Anat. (Ziegler's), 1905, xxxviii, 395. 
form methemoglobin on contact with blood. The amount, however, is, as previously stated, usually too small to give a characteristic sfectrum.

The liver and kidneys showed practically no changes on microscopical examination. A large number of sections from the liver showed a very few small necroses and a little fatty degeneration. The kidneys also were in good condition with only a slight cloudy swelling of the tubular epithelium and some congestion of the tufts in the capsules and of the intertubular vessels; but there were no casts in the tubules and no evidences of interstitial nephritis.

The heart muscle showed a small amount of fat infiltration, but was otherwise normal.

The interesting lesions were those in the lungs. As stated above, there was a Iobular pneumonia chiefly in the lower lobes. Between the areas of consolidation there was a very marked emplysema with absorption of a large number

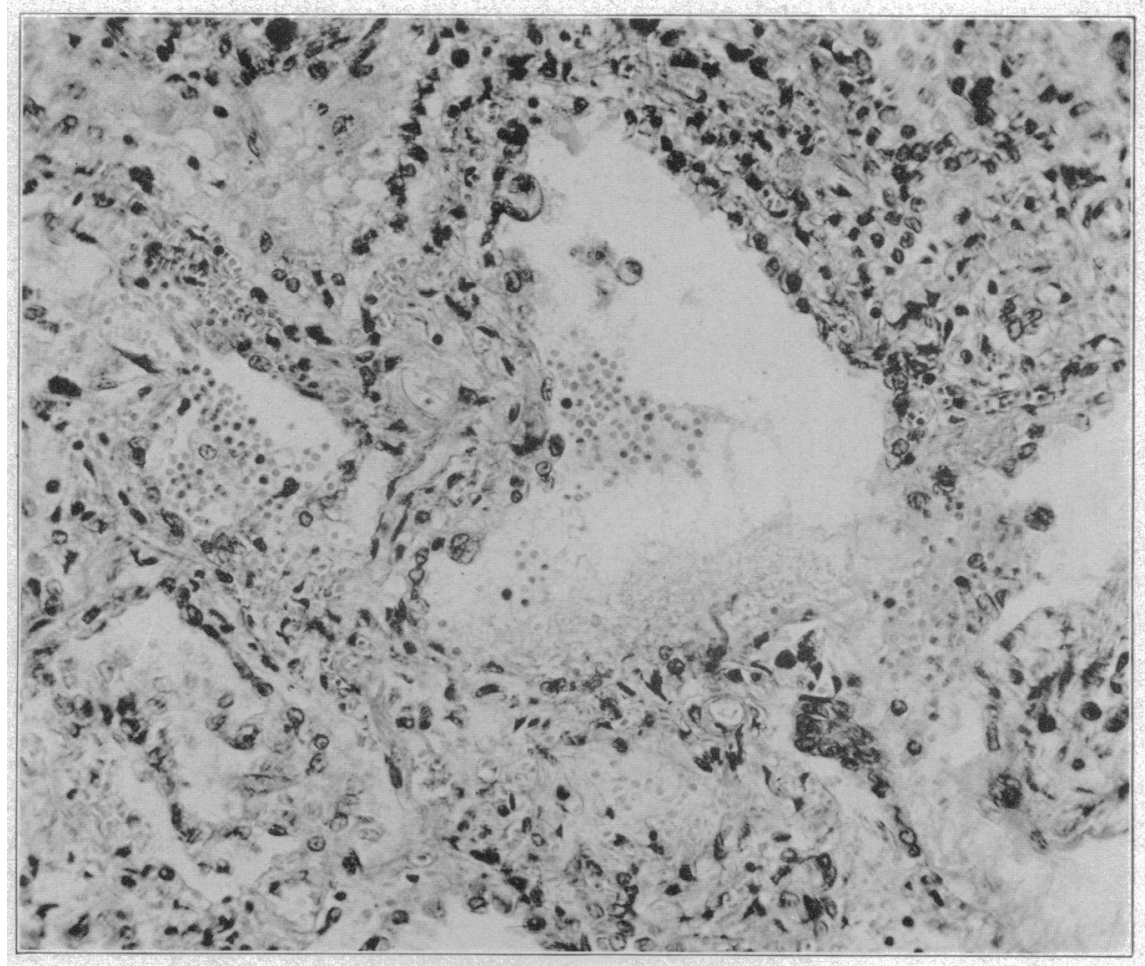

Fig. 6.-Case D. Hemorrhagic portion of lung. $\times 250$.

of alveoli so as to form large cavities easily visible to the naked eye, a phenomenon which regularly occurs not only in human beings, but also in experimental animals. (Figs. 1 and 2.) The mucous membrane of the trachea and bronchi was desquamated over extensive areas. (Fig. 3.) In some places fragments of the epithelial lining could be found still adhering to the walls or collected in masses in the lumen, with extreme edema of the subepithelial connective tissue. Occasionally a bronchus was found into which had grown a cellular plug largely filling the lumen. About the smaller bronchi were areas of consolidation, the alreoli being filled either with a transparent albuminous mass, or with fibrin containing a few leukocytes, or witl desquamated a?veolar epithelium. (Fig. 4.) ln some places the epithelium was full of phagocyted blood-pigment. (Fig. 5.) 
Throughout, many alveoli contained red blood corpuscles. (Fig. 6.) The capillaries in the walls were distended with blood and the walls themselves were very edematous and much thickened. In places there was evidence of beginning regeneration of the alveolar epithelium which either lined the alveolus (Fig. 7) in the form of a thin flat layer of cells much more prominent than is seen in a normal lung, or occurred as swollen prominent hemispherical cells protruding into the lumen Sometimes these cells formed considerable masses or were fused into syncytial bodies. (Fig. 8.) A true organizing pneumonia could hardly be said to be present. The fibrinous plugs occasionally became very dense and were covered with new epithelium, and in rare instances were penetrated by fibroblasts, but this was not at all a predominant lesion. In other portions of the lung the alveolar structure had entirely disappeared, the lung being quite collapsed and the regenerating epithelium showing as solid syncytial masses or as strands of cells lying in the fairly dense pulmonary tissue. (Fig. 9.) The upper portions of the lungs were fairly well acrated and showed a. moderate emphysema, but no

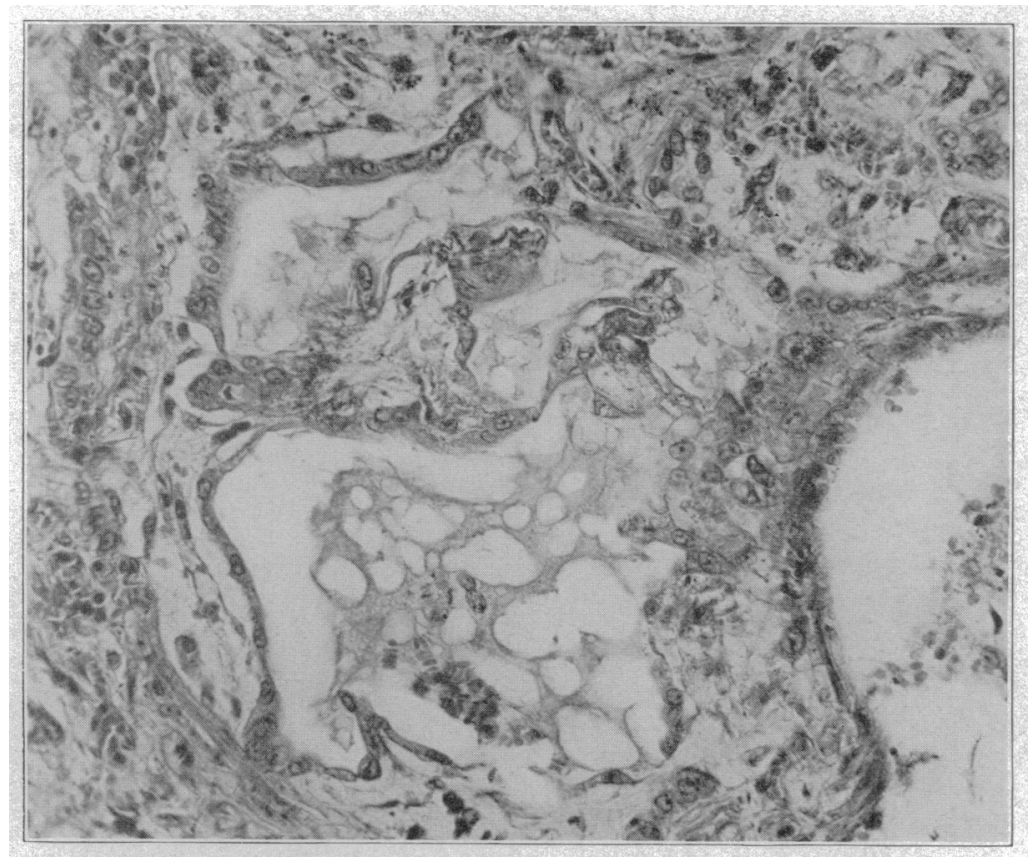

Fig. 7.-Case D. Regeneration of alveolar epithelium. $\times 250$.

other lesions. The bronchial lymph-nodes were edematous and heavily pigmented; but otherwise normal. In the smaller vessels of the lungs there were a number of parietal thrombi; occasionally a thrombus filled the entire vessel; and there was some proliferation of the endothelial lining, showing that these thrombi were undoubtedly ante mortem. Similar thromboses can be easily induced in animals by the inlialation of nitrogen tetroxid fumes. Obviously, no cultures could be made from the lung, but a large series of sections were stained by the various methods used for detecting bacteria, and no organisms cou'd be found. The condition was evilently a non-progressive pneumonia due to irritation of the corrosive gases inhaled, and showing a tendency toward repair.

The history and clinical symptoms of the case and the nature of the lesions, which correspond exactly with those described in other cases of nitrogen tetroxid 


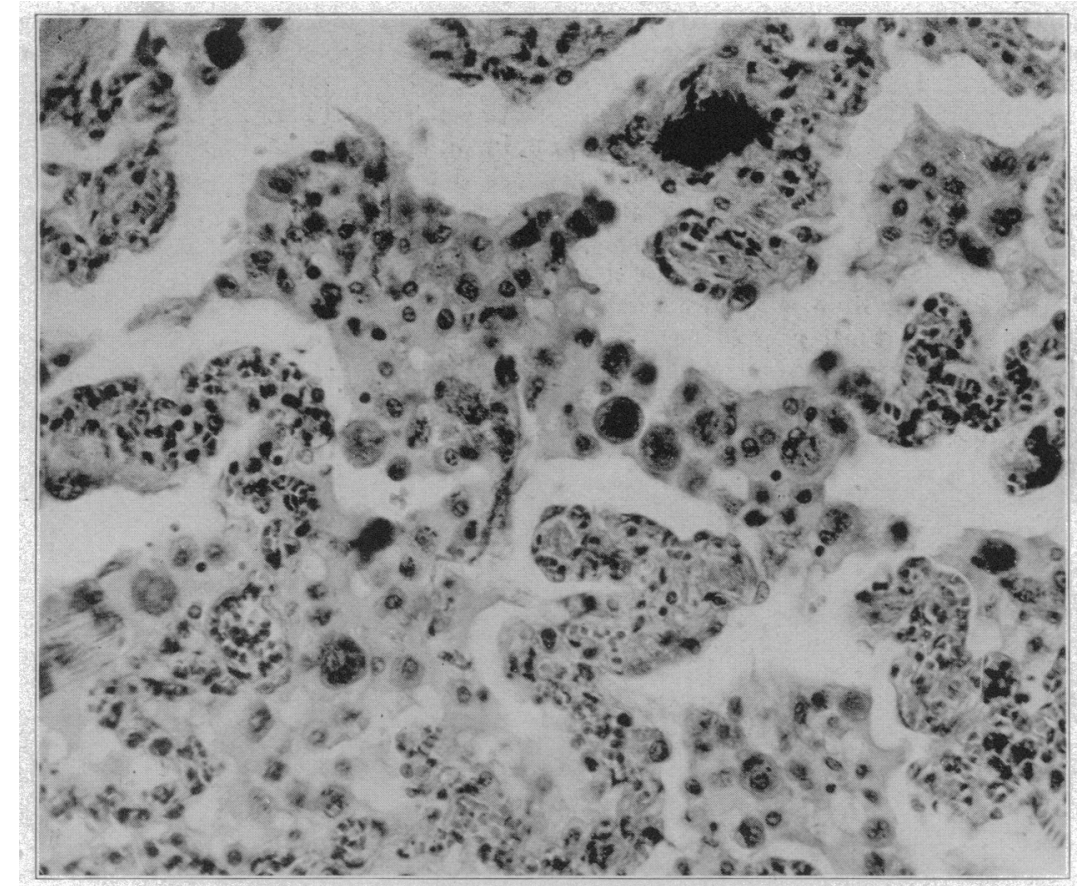

Fig. 8.- ('ase D. Cellular exudate. $\times 250$.

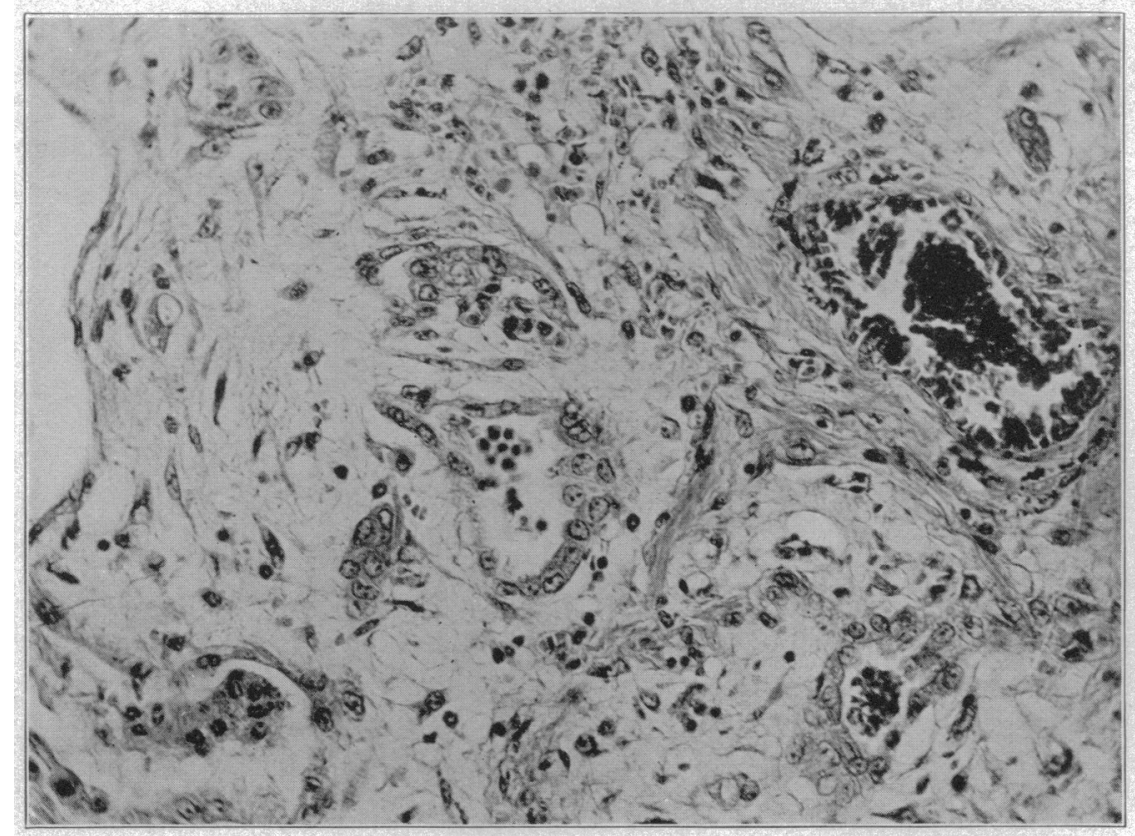

Fig. 9.-Case D. Collapsed and edematous lung with new growth of alveolar epithelium and connective tissues. $\times 250$. 
poisoning, and the confirmatory results of animal experimentation which follow, point, it seems to me, to the conclusion that deatil in this case was unquestion. ably due to the accidental inhalation of this gas.

\section{CASES FHOM THE LITERATLRE}

An examination of the literature of nitrogen tetroxid poisoning shows only a moderate number of carefully studied cases. Most of the earlier ones were insufficiently examined, and in few are there any microscopical reports.

Schubert, in 1911, was able to coliect 213 cases of poisoning by nitrogeri tetroxid, of which fifty-five were fatal. With very few excep-

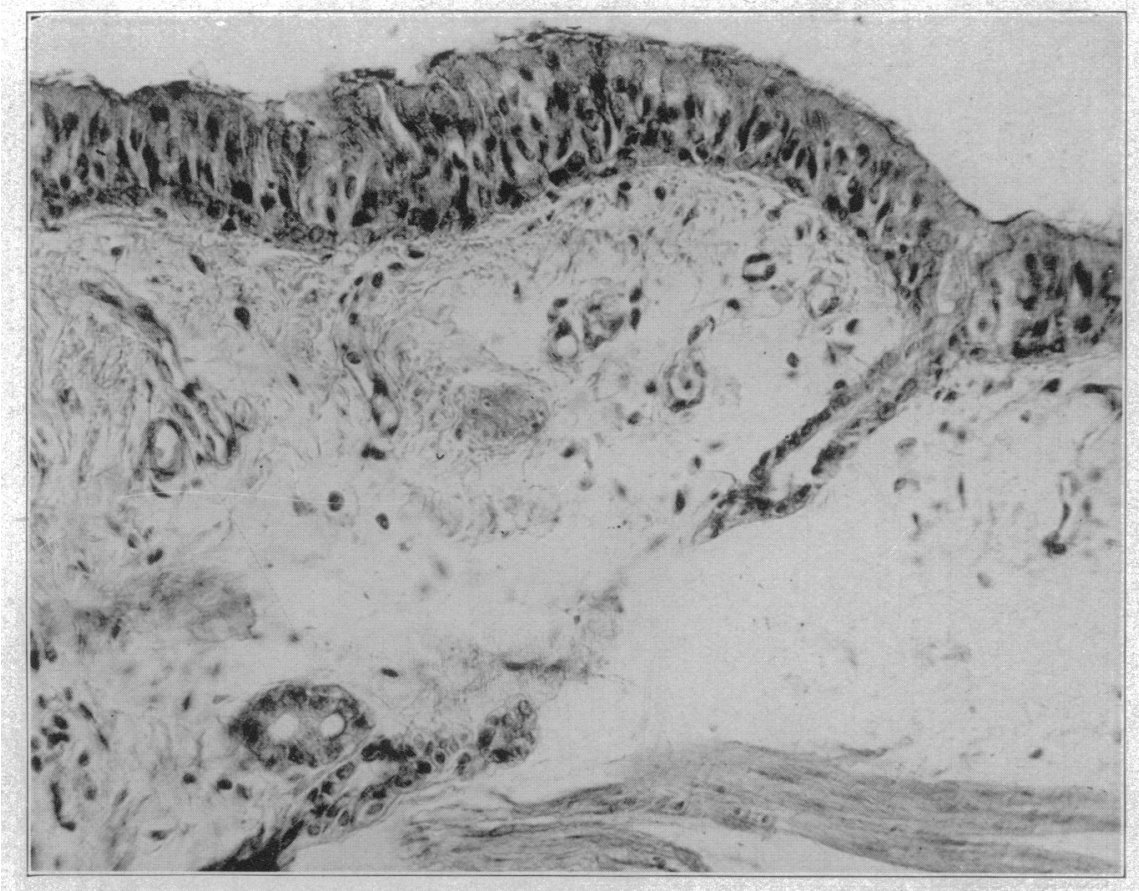

Fig. 10.-Dog 4. Bronchus showing epithelium and cilia still remaining, but marked edema and congestion of submucosa. $\times 300$.

tions, all these cases occurred in the last fifteen years, and chiefly in the German Empire. There are no doubt many cases which have never been published for obrious seasons. Concentrated nitric acid is extensively used in the manufacture of gun-cotton, nitroglycerin, smokeless powder and celluloid, and it is said that many cases of poisoning occur in these factories. The following reports include only those in which an autopsy was performed.

The most carefully studied cases are the four which were reported from Cologne following the breaking of some carboys of nitric acid in a 
smiall room about $12 \times 6 \times 8$ feet. The clinical histories were reported by Savels; $;^{4}$ the pathological findings by Loeschcke, ${ }^{5}$ and the medicolegal aspects of the cases by Czaplewski ${ }^{6}$ and Schubert. ${ }^{7}$ While the reports do not wholly agree in minor details, the important findings are given so fuliy that a very satisfactory picture of poisoning of this type is presented. For this reason a full abstract of these cases is given here.

Case I.-B. K. The patient was a man, 42 years old. He was cleaning out the room after the accident and remained in it for about twenty minutes, when he felt weak and went home. He vomited and had diarrhea, and some hours after the accident was seized with intense dyspnea, cyanosis, and cardiac weakness. He died in the hospital about five and a half hours after he had

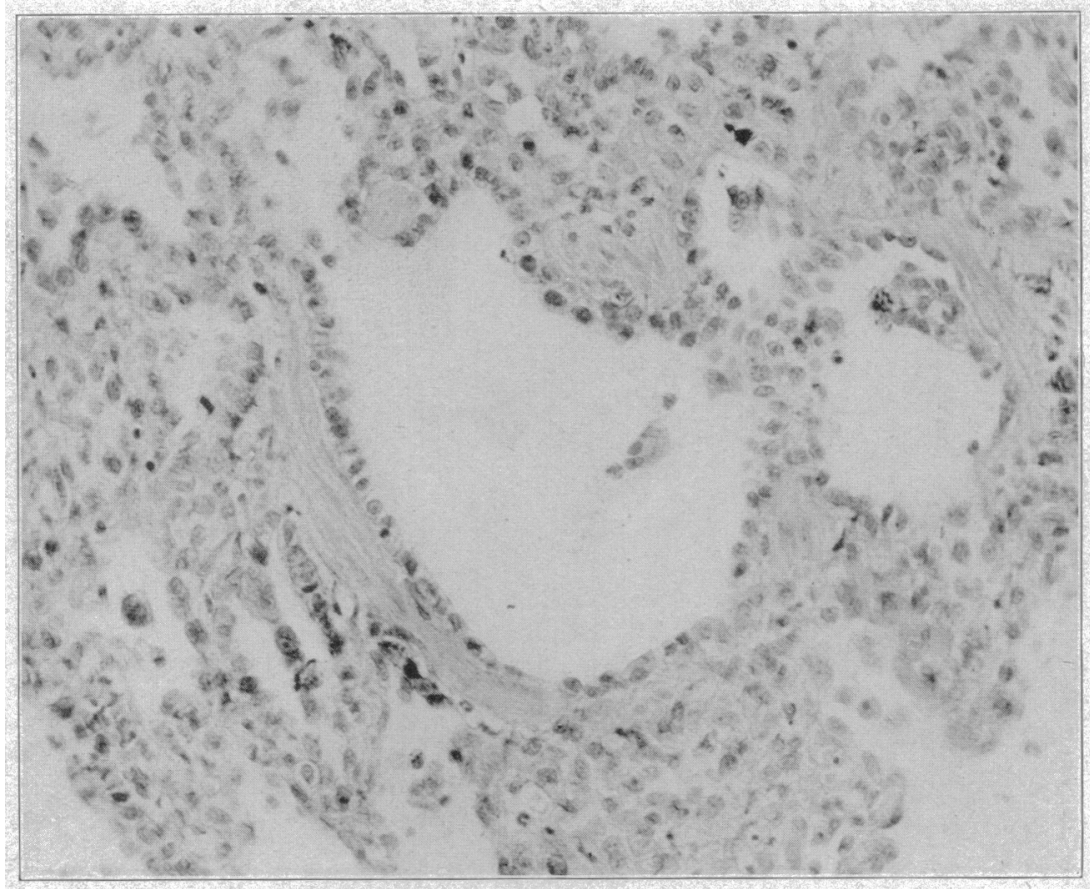

Fig. 11.-Dog 4. Terminal bronchus and alveoli with swollen and desquamated epithelium. $\times 300$.

left the room in which he was exposed to the vapor. The autopsy showed chiefly emphysema and edema of the lungs. Section of the lung had a violet red color and showed many bright-red spots which were especially well aerated. A very abundant, fcamy, pale-red fluid exuded from the cui surface. In the bronchi and trachea there was much thin, foamy secretion with small amounts of thick mucus. The mucous membrane was a bluish-red color. Microscopically the brain showed

4. Savels: Deutsch. med. Wchnsehr., 1910, xxxvi, 1754.

5. Loeschcke: Beitr. z. path. Anat. (Ziegler's), 1910, xlix, 457.

6. Czaplewski: Vrtljsch. f. gerichtl. Med., 1912, xliii, 356.

7. Schubert: Ztschr. f. Med.-Beamte, 1911, xxiv, 557. 
no lesions except small perivascular hemorrhages. The kidneys showed intense congestion with some necrosis in the ascending branch of Henle's loop. The lungs showed marked emphysema with intense congestion; the alveolar epithelium was very largely desquamated and lay in masses in the alveoli. In the alveolar walls and also in the lumen there were numerous red cells and abundant leukocytes, and in some regions the walls of the alveoli were covered with a hyaline exudate. The mucous membrane of the bronchi was not altered microscopically. The liver showed nothing especially noteworthy.

CASE 2.-Sch. Th. The patient was 41 years old and had always previously been well. While cleaning out the cellar he noticed no discomfort except irritation in the chest and occasional tendency to cough. After the accident he had a mild headache, some coughing without sputum, and a feeling of weakness.

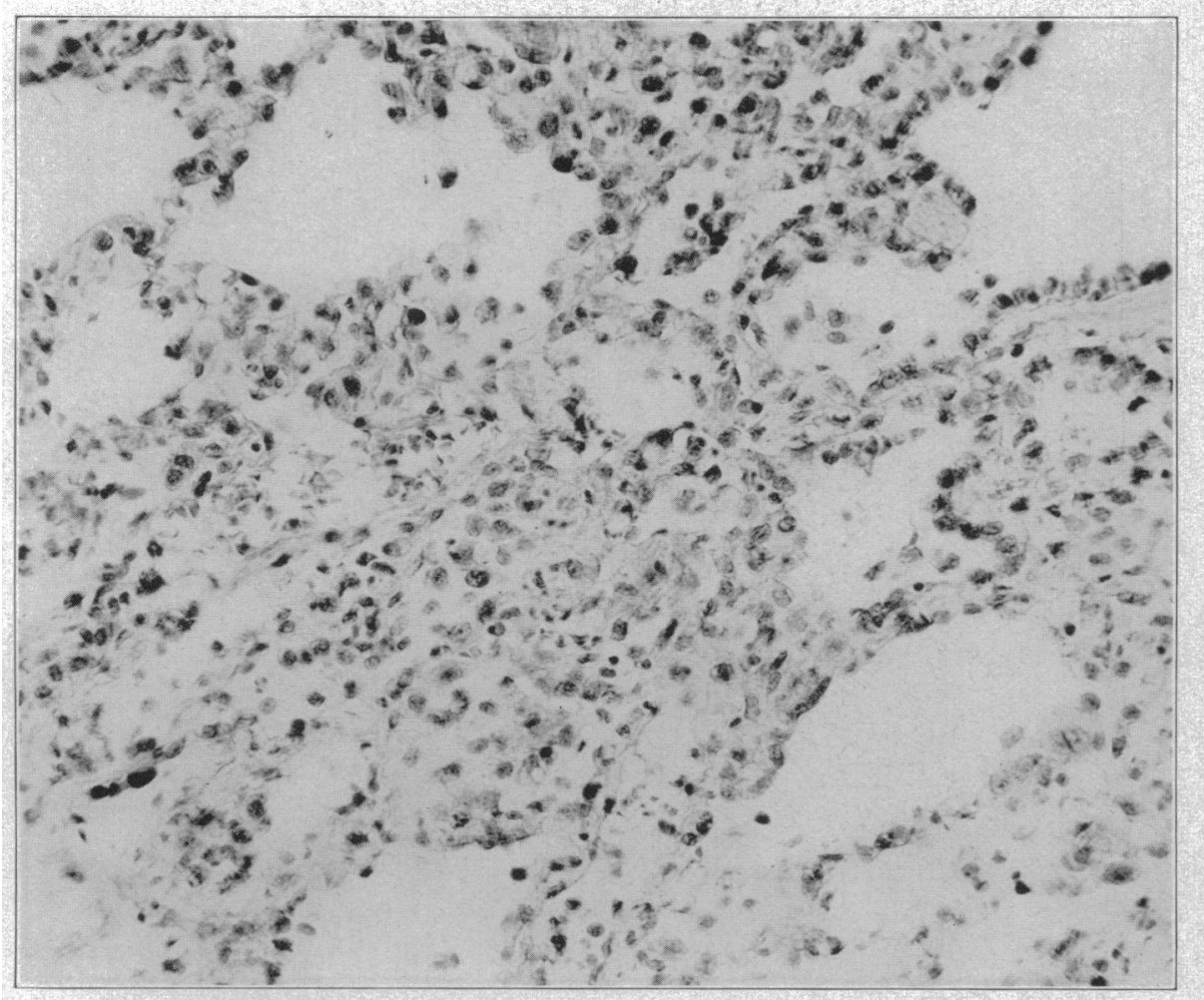

Fig. 12,-Dog 4. Desquamation of alveolar epithelium. $\times 300$.

Three hours after the accident he had pain in the chest and a chill, and went to bed, but could not remain there on account of extreme dyspnea, a feeling of pressure on the chest, and violent coughing. He was taken to the hospital, and on examination there was found to be extremely pale and cyanotic. The pupils were dilated, and reacted slowly to light; but otherwise there were no nervous symptoms. His mind was clear. Breaihing was rapid and difficult with marked action of the auxiliary respiratory muscles. Over the lung there were sonorous percussion notes, with fine inspiratory crackles; no coughing; no sputum. The temperature was $101.1 \mathrm{~F}$.; the pulse was rapid, 108, small and soft. The heart-sounds were pure. The patient had a venesection of 250 c.c. of blood, 
which was strikingly dark and tar-like, and coagulated rapidly, but spectroscopically showed only bands of oxyhemoglobin. There was a slight inerease in the number of white cells. In spite of oxygen inhalations the patient became rapidly worse; he complained of a feeling of compression of the larynx, of intense thirst, and of frightful dyspnea. The face was covered with sweat, the eyes protruded, and he could scarcely speak; the pulse became more rapid, rising to 140 , and the temperature was $101.8 \mathrm{~F}$. He died in coma forty-eight hours after the accident with signs of edema of the lungs, the final temperature being $102.9 \mathrm{~F}$.

'The urine passed during his stay in the hospital was small in amount, highly colored, faintly acid, free from albumin, and contaired only 1 per cent. of sugar. The ammonia was somewhat increased; acetone positive; aceto-acetic tests negative.

Autopsy showed the lungs to be greatly distended, covering the pericardium; they were very heavy. The pleural surface was smooth. Sections showed a large

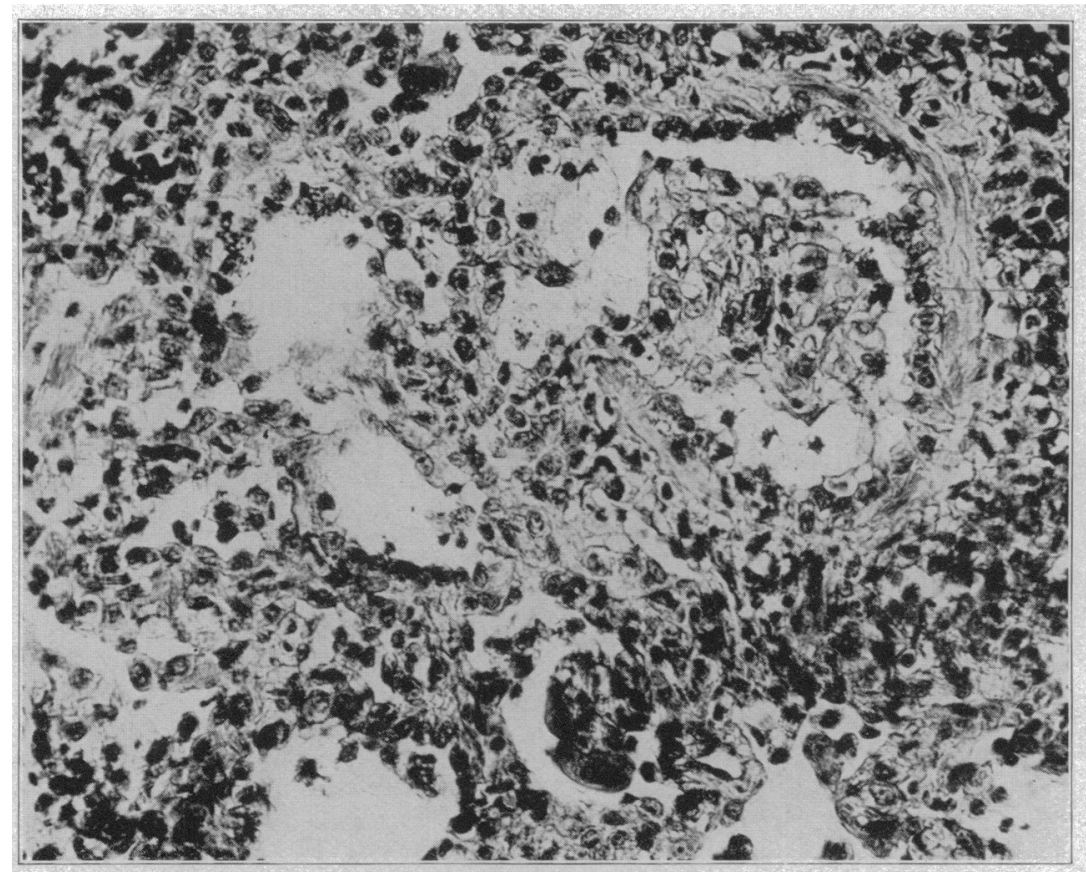

Fig. 13.-Dog 4. Intrabronchial growth of epithelium. $\times 300$.

amount of edema and congestion, with a general reddish color of the surface and numerous small granular areas scattered throughout, which were of a bright red color and emphysematous. The mucous membrane of the bronchi, trachea and pharynx was of a bluish-red color. The bronchial lymph-nodes were large and swollen. The brain was intensely congested; otherwise there was no change. The kidneys also were intensely congested, with no otler change evident. The liver was pale and yellowish-brown and blackened on the application of ammonium sulphid.

Microscopically there were no changes in the brain. In the lungs the alveoli showed great variations in the dimensions. There vere areas of relatively narrow alveolar spaces filled with exudate, partially fibrinous, partially hyaline, and containing many red and white cells. Between such areas there were large, greatly 
dilated spaces, chiefly without content, apparently due to a traumatic emphysema, as shown by the spaces where the torn walls were hyaline and thrombosed vessels lay near the site of rupture. The epithelial coating of the alveoli was desquamated; that of the bronchi was present in areas though showing much degeneration; in other places it was entirely missing. All the vessels of the lung were greatly distended with blood. The spleen showed no special lesion except that there were many phagocytic cells containing blood pigment. The liver showed cloudy swelling with numerous areas of degeneration. At the periphery of these foci of necrosis there was already beginning repair with mitoses in the liver cells. In the kidneys the gloneruli tufts were very much distended, filling the entire capsule. In some parts of the capsule there was a small amount of hyaline exudate with desquamation of the capsular epithelium. The cells of Henle's loop were completely necrotic and in the convoluted tubules there was much yellowish

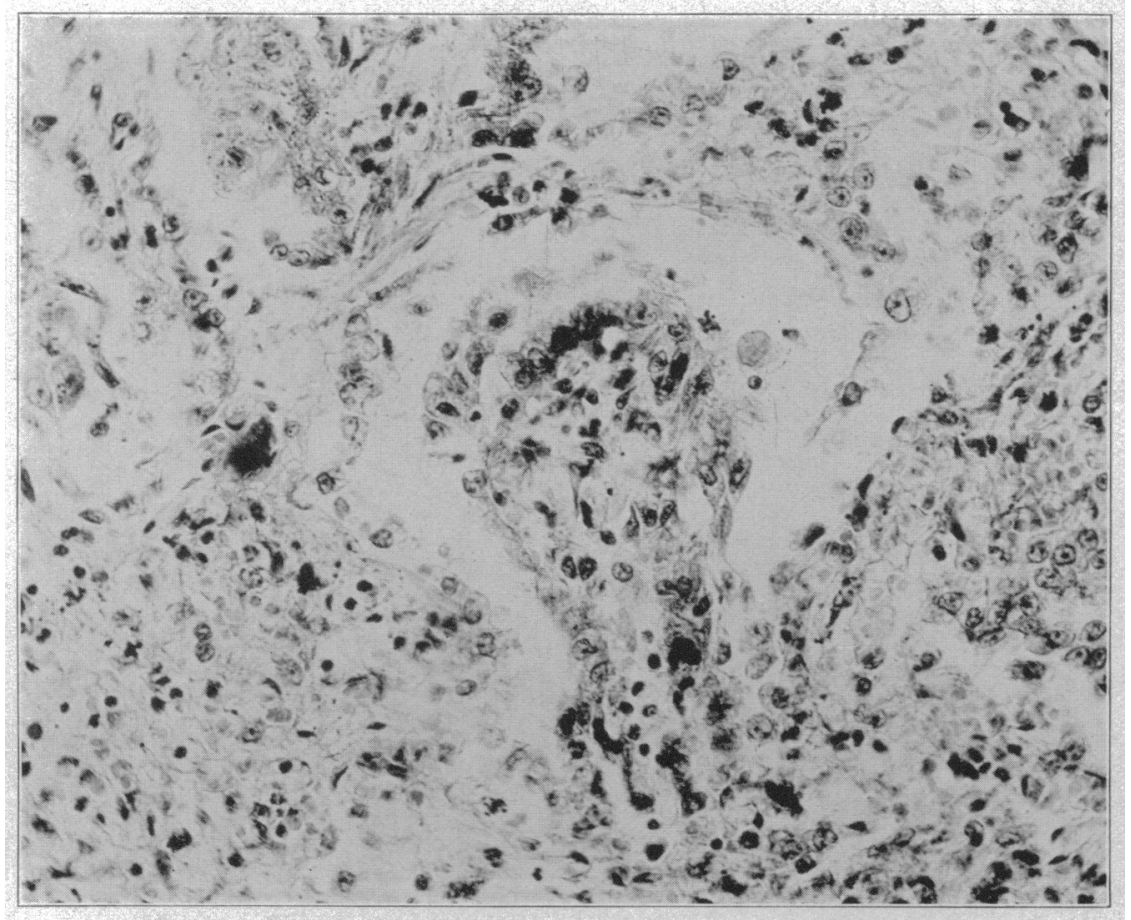

Fig. 14.-Dog 4. Intra-alveolar growth of epithelium. $\times 300$

granular pigment. Some of this pigment was contained in the tubular epithelium. Hyaline spherical granules were also found in the lumen of the tubules with an occasional hyaline east.

CASE 3.-W. W. Previous to the accident the patient had always been well. On entrance to the hospital he complained of moderate pains in the chest, coughing and slight dyspnea. On examination he was apparently a healthy man in good condition. The skin of the face was reddish; the mucous membranes were slightly cyanotic. Breathing was a little rapid, percussion sonorous. All over the lungs there were sibilant râles, with a few moist râles over the lower right chest. The pulse was 108 . There was some distention of the abdomen with diffuse tenderness. The stools were thin, and ytlowish. During the day the 
patient expectorated some yellowish sputum, and some faintly bronchial breathing appeared over the upper lobe of the right lung; and also in the left lower lobe there was moderate dulness with many respiratory râles. The temperature rose to $39 \mathrm{C}$. The blood obtained on venesection was dark and of a bluish color, but spectroscopically showed only oxyhemoglobin. There were no abnormalities in the urine. Two days after the accident the patient's mind was clear; he suffered from fever between 39 and $40 \mathrm{C}$. with irregular remissions. There was bronchial breathing over the right upper lobe and left lower lobe, and edema over the rest of the lung. The sputum was brownish-red, thin and foamy, and looked like pneumonic sputum, but no pneumococei could be found. Five days after the accident the patient had a moderate delirium. Venesection seemed to improve the general condition, but six days after the accident the heart action

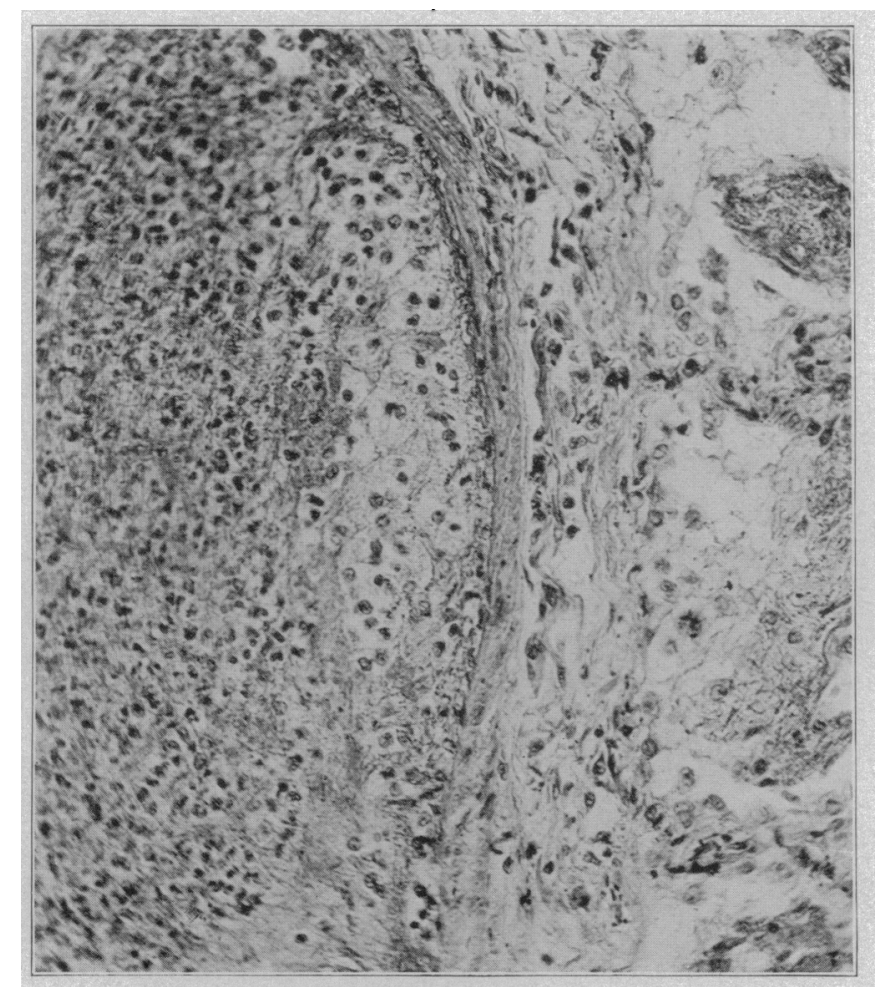

Fig. 15.-Dog 4. Thrombus in a vessel; blood elot to the left; lung tissue to the right. $\times 300$.

became very feeble, the pulse was irregular, and the condition progressively became worse; the dyspnea increased, with restlessness and picking at the bed elothes. The patient died seven days after the accident with evidences of pneumonia and cardiac failure. At no time did the urine show any important changes.

The diagnosis at autopsy was croupous pneumonia in the upper lobe on the right side and the lower lobe on the left; edema of the lungs; localized necrosis in the liver. The upper lobe of the right lung sinowed fresh adhesions. Both lungs were very large and heavy. On section the whole right upper lobe was granular, in a state of red hepatization, and absolutely free from air. There 
were fibrinous plugs in the bronchi. The middle and lower lobes were edematous and contained some areas of pneumonia. The left upper lobe and the upper part of the lower lobe were extremely emphysematous. The lower part of the left lower lobe was largely granular, free from air, and in a state of red hepatization, with a few fibrinous plugs in the bronchi. The trachea and bronchi were filled with large amounts of foamy fluid. The liver was enlarged and intensely congested, and showed on cross section a grayish-red, cloudy appearance with some grayish areas scattered throughout. Both kidneys were very large, the capsules slightly adherent, the markings indistinet. The spleen showed intense congestion.

On microscopical examination of the lungs the alveoli in the pneumonic portion were partly of normal dimensions, partly very greatly dilated and filled with exudate which consisted, chiefly of fibrin, but in places, of a smooth hyaline material. In this exudate there were found in varying numbers cells chiefly of polynuclear structure. In some regions the staining capacity of the alveolar wall was lost and in these areas the exudate seemed to have spread from one alveolus to another. The leukocytes were especially abundant here. Some of the blood-vessels were thrombosed, but the blood-supply of the consolidated areas was slight. The alveolar epithelium was absent over considerable areas. In some places there were isolated epithelial cells with long projections extending over the alveolar wall, evidently a beginning regeneration. The projections came into contact with the nearest epithelial cells, and in this way large areas of alveolar substance had been covered with a few flat cells. In areas where the regeneration had gone further the cells were thicker and more cubical, though at the periphery of these areas they still retained the flattened form. The cell boundaries were often so obseured as to suggest syncytial structure. Finally, some alveoli were entirely covered with cubical epithelium, occasionally much higher than the normal. No mitoses were observed. The epithelium of the smaller bronchi was still preserved. In the portions of the lung not involved in the pneumonia the alveoli were partly free from exudate and partly contained larger or smaller amounts of fibrin, leukocytes and red cells. The fibrin in places had undergone hyaline degeneration. The epithelial regeneration in these areas had progressed further than in the hepatized portions, so that most of the alveoli were covered with a thin, flat epithelial layer. No bacteria could be found.

Section of the liver showed areas of neerosis in the center of practically all of the acini. The central vein was frequently thrombosed. Polynuelear leukocytes were seattered through the necrotic tissue. The liver cells at the periphery of the acini were large, their nuclei rich in chromatin, and showed mitoses. Pigmentation of the liver cells was slight in amount.

The glomeruli of the kidney were large; the capsules were thin, with moderate desquamation of the capsular epithelium. In the capsules were found finely granular masses of albumin, in places compressing the glomerulus. The epithelium of the convoluted tubules was swollen, and many cells showed imperfect staining qualities. The lumen of the tubules contained granular masses of albumin. In Henle's loop there was extensive necrosis of cells, many of which had fallen off in the lumen. The collecting tubules showed numerous small homogeneous casts composed apparently of masses of tubular epithelium. They stained dark with hematoxylin and black with silver; in other words, they probably contained some phosphate of lime, a condition found chiefly in cases of poisoning with mercuric ehlorid.

CASE 4.-A. S. This patient was not engaged in cleaning up the acid, which had been completed, but as night watehman had to pass through the cellar every hour. During the day following his night work he complained of pain in the chest and abdomen. When examined he was found to have symptoms of a severe bronchitis with very rapid and irregular heart. He complained also of dizziness and faintness and vomited a good deal. Twelve days after the accident he was seized suddenly with a cerebral hemorrhage and died three days later. Autopsy showed extensive arterioselerosis with an area of red softening 
about $2 \mathrm{~cm}$. in diameter in the left posterior portion of the internal capsule. The hemorrhage was encapsulated but had broken through into the ventricle, which was filled with fluid blood. In this case the influence of the nitric oxid fumes was probably entirely secondary, as the lungs showed no lesions, but the coughing and vomiting may have induced the cerebral hemorrhage.

This completes the Cologne series. The following reports, while in the main less complete, are of sufficient importance to warrant their inclusion:

CASE 5.-This is an exceedingly interesting case reported under the title "bronchiolitis fibrosa obliterans." "The patient survived the inhalation of the nitrogen tetroxid for nineteen days, so that the description shows well the nature of the lesions and the repair which takes flace in a long continued case. From the microscopical findings given it is evident that the regeneration of the alveolar epithelium was nearly complete, though the cut shows some alveoli still filled with large cells; but in any case the desquamative lesions of the lungs were less striking than the organization and closure of the bronchi and small vessels with new-formed tissue.

The patient was a-laborer, 25 years old, who was previously healthy; he inhaled the fumes from a vessel containing nitric and sulphuric acids with a piece of brass casting. (Such a combination gives nitrogen tetroxid vapors.) Immediately afterward he had a severe attack of coughing with a feeling of oppression on the chest and a good deal of pain in this region. During the course of the night following he was seized with intense dyspnea and entered the hospital. On admission it was noted that he was intensely evanotic; temperature, 102; pulse, 112; respirations, 72 ; blood-pressure, $105 \mathrm{~mm}$. There was slight dulness over both lungs posteriorly and coarse and fine crepitant râles all over. The patient complained of a feeling of burning behind the sternum. The sputum was small in quantity, reddish-brown and mucoid. The following day the temperature was normal and the cyanosis and dyspnea diminished. Respiration went down to 60, and the pulse to 108. The râles in the anterior portion of the chest diminished. Two days after the accident the patient coughed up rust-colored balls of sputum, showing very few diplococei. From the third to the seventh day after the accident the temperature rose slightly, and there was subcutaneous emphysema of the anterior thorax between the second and fifth ribs. Eight days after the accident the subcutaneous emphysema disappeared and the patient was in fairly good condition without symptoms, except a few râles in the chest, until four days later when the cyanosis and dyspnea returned. The respirations rose to 60 and the pulse to 120 . The condition was not so serious as at the first attack. The râles returned with a change in the percussion note. The sputum was reddish-brown and mucoid. The patient died nineteen days after the accident.

At autopsy, the heart showed slight hypertrophy of the right side. The lungs were very much dilated, so that their borders touched each other at the level of the second and fourth ribs. A few fibrinous adhesions at the left apex and left lower lobe. On the surface of the lung there were a number of somewhat depressed bluish spots of irregular outline which contained less air than the rest of the tissue. On section, these were edematous. Scattered throughout the lung also were small areas of hepatization. In addition there were numerous small nodules of a transparent gray color looking a good deal like tubercles. The small vessels contained thrombi. The right lung also was voluminous and distended with air. In the middle lobe there was an area of hepatization about the size of a cherry. On the surface were numerous bluish-red spots, on the pleural surface of which were small fibrinous coagula. The cut surface showed

8. Fraenkel: Deutsch. Arch. f. klin. Med., 1902, lxxiii, 484. 
many irregular dark-red areas, and besides these, small grayish-white nodules attached to the smaller bronchi. There was an emphysema of the lung with numerous areas 2 to $3 \mathrm{~mm}$. in diameter. The smaller arteries showed thrombi adherent to the walls. The other organs showed nothing but congestion.

Microscopical examination of the lung showed a large number of thrombosed small arteries and the hemorrhagic and edematous areas which Fraenkel was inclined to interpret as small infarcts. In the fine terminal bronchi there was a marked epithelial desquamation, the cells often filling the entire lumen. The larger bronchi also showed considerable loss of epithelium. In the finer branches of the terminal bronchi there was a growth of connective tissue reducing the lumen in many cases to a small slit, covered in part with high cylindrical epithelium of the bronchial type. The remainder of the lung showed either emphysema, edema or collapse. In the denser portions the alveolar walls were thickened with connective tissue, especially near the bronchioles. Some of the vascular thrombi had undergone complete organization with the formation of connective tissue. There was no report of any bacteriological examination of the lung tissues.

In a later paper Fraenkel ${ }^{9}$ reports three more cases of so-called bronchiolitis obliterans fibrosa acuta, one in a plasterer who inhaled a large amount of lime and other dust, and the second in a man working in a drug store. The history of this latter case was very imperfect and Fraenkel says that it was not possible to exclude the inhalation of some irritating substance as the cause of the disease. In the third case reported no history was obtainable, and the diagnosis was made solely on the clinical symptoms of intense dyspnea, cyanosis and emphysema. Death occurred on the fourteenth dav. Microseopical examination of the tissues showed chiefly obliteration of the bronchi.

The report is not very clear, but apparently all these patients lived for at least two weeks. The writer also observed another case with similar symptoms due to the inhalation of large quantities of dust from chlorid of lime. He says, however, that the disease is not always due to the inhalation of irritating gases or powders, and that measles and whoopingcough occasionally produce in children a very similar anatomical picture. In ordinary lobar pneumonia such a closure of the bronchi by the ingrowth of connective tissue does not occur or is very limited in extent, even in cases in which resolution is prolonged over weeks.

CASE 6.-The patient, ${ }^{10} 23$ years old, a tinner by trade, inhaled the fumes from a mixture of hydrochloric and nitric acids. He had a slight oppression in the chest but continued at work for nine days though not feeling well. On the tentk day he had a good deal of dyspnea and entered the hospital. When examined he showed very marked cyanosis, especially of the face. Thoracic movements were limited during respiration, which was iapid and shallow. The pulse was 140 , very soft and irregular. Temperature was $102.2 \mathrm{~F}$. There was dulness over the chest. The patient appeared moribund. The sputum was abundant, yellowish and lumpy. There were physical signs of emphysema with many moist râles over the lungs. The next day respiration went to 50, the temperature was about $100.4 \mathrm{~F}$; the cyanosis and dyspnea increased, and the patient died twenty-six days after the exposure to the fumes. At autopsy the lungs did not collapse on opening the thorax. There were small hemorrhages in the pleural surfaces of the lower lobes. On section the lungs were densely sprinkled with small grayish nodules 1 to $2 \mathrm{~mm}$. in diameter, which surrounded the smaller

9. Fraenkel: Berl. klin. Wchnschr., 1909, xlvi, 6.

10. Edens: Deutsch. Arch. f. klin. Med., 1906, lxxx, 598. 
bronchi. The mucous membrane of the larynx, trachea and smaller bronchi was intensely irritated, and in many places had disappeared. No other lesions were found in the body.

Microscopic examination showed marked inflammatory lesions of the trachea and bronchi with congestion and edema. In the lung there were numerous small chronic pneumonic areas with the formation of granulation tissue. The alveoli at the periphery of the pneumnnic areas contained a cellular exudate chiefly composed of desquamated alveolar epithelium, the cells being of large size and often loaded with pigment. Some of the alveoli also contain fibrin. There was marked inflammation of the septa of the alveoli with edema, fibrinous exudate and leukocytes; the vessels were greatly distended. Thrombi were not noticed, and bacteria were not found in the lung sections.

This case is particularly interesting because of the long continuance of the disease, showing the latter stages of the process, death usually occurring much earlier in the course of the intoxication.

CASE 7.-Paul ${ }^{11}$ reports the case of a laborer, 32 years of age, who was ordered to clean the deposit out of a lead chamber. This deposit consisted chiefly of lead sulphate mixed with some sulphuric acid, the mixture giving off vapors of some of the nitric oxids. Fir this reason it was necessary that the workers leave the chamber every few minutes as the stirring up of the mud set free the fumes. The chamber had been cleaned some two hundred times under exactly the same conditions as on the occasion of the accident. There were two other workers also in the chamber who were not in the least affected. The patient entered the chamber three times, remaining for periods of ten to twelve minutes. About 6 o'clock he went home without complaining in the slightest. Some hours afterward, however, he was seized with dyspnea and very severe coughing. He attempted to go to work the next morning, but collapsed on reaching the factory. The patient was examined by a physician after his collapse at the factory and was found to be intensely dyspneic with paroxysms of coughing. The sputum was brownish-red in color, having previously been bright yellow. The lungs showed some dulness over the lower lobes, but no bronchial breathing, only fine râles all over. The pulse was 110 , very soft and small. Temperature was subnormal. About thirty hours after the exposure he had a severe seizure with extreme cyanosis, great restlessness and occasional delirium. He went into coma and died about forty-six hours after exposure to the gases with the symptoms of pulmonary edema.

Autopsy showed intense congestion of the meribranes and substance of the brain with numerous punctate hemorrhages in the substance. The mucous membrane of the pharynx, trachea and larynx was very dark red and covered with sticky mucus. The heart's blood was very dark; the organ was dilated and the muscle was soft. The pleura of the right lung showed a number of small ecchymotic areas about $1 \mathrm{~cm}$. in diameter. On section a large amount of reddish, foamy fluid escaped from the lung which was extremely edematous, with the peripheral portions showing a considerable amount of emphysema. Section of the left lung showed the same, but the pleura was adherent all over the thorax with old adhesions. The stomach showed a small hemorrhagic erosion at the greater curvature. There was no lesion except intense congestion of the viscera. No microscopical examination was reported.

CASE 8.- Schmieden ${ }^{12}$ reported the case of a 24-year-old laborer who was exposed to nitrogen tetroxid fumes for one hour following the breaking of a carboy of nitric acid and attempts to stop the action of the acid by the use of sawdust. He noticed only slight dyspnea after finishing the work and on his return home

11. Paul: Wien. klin. Wchnschr, 1895, viii, 665 .

12. Schmieden: Centralbl. f. klin. Med., 1892, xiii, 209. 
some cyanosis. During the night the patient was unable to sleep on account of increasing dyspnea and very severe cough. On admission to the hospital he was found to be intensely cyanotic; respirations, 78 ; breathing chiefly abdominal with marked movements of the alæ nasi and the sternocleidomastoid and scalenus muscles. Percussion note was tympanitic. Fine râles were heard all over the chest. The sputum was abundant, thin, rusty-brown in color like pneumonic sputum after edema of the lungs supervenes. The pulse was 112 and soft. Blood taken from the ear was brownish-black in color and on dilution in water became bright red; spectroscopically there was nothing abnormal. The patient died in coma thirty hours after the inhalation of the acid fumes with symptoms of edema of the lungs.

At autopsy the lungs were extraordinarily congested and infiltrated throughout with bloody edematous fluid. The mucous membrane of the bronchi was congested. The vessels of the lungs were distended with dark red and black thrombi. There was intense congestion of the pial veins and the arteries at the base of the brain. There was a yellowish slough on the mucous membrane of the stomach near the cardia. No microscopical eximination was made.

CASE 9.- Kockel $^{13}$ reported the case of an apparently healthy male, 65 years old, who had worked for about one hour in a room in which a large quantity of nitric acid had been spilled. Except for a little coughing and dryness in the throat there were no symptoms until six hours after exposure, when he was seized with rery severe dyspnea, coughing, and a feeling of great anxiety. The symptoms increased rapidly with intense cyanosis, and the patient died two hours later. At the autopsy there was congestion of the meninges; in the posterior portion of the external rim of the right lenticular nucleus there was an area of softening the size of a hazel nut, apparently an old lesion. The heart muscle was soft; the cavities were much dilated and filled with dark fluid blood. The left lung was very voluminous; the tissues were soft and tore easily, and on cut section were very dark grayish-red. There was a good deal of edema and very little air in the alveoli. The right lung also was very voluminous; the upper lobe dark grayish-red and very much congested with only a moderate amount of fluid in the alveoli. The mucous membrane of the larynx, trachea and bronchi was bright red and much swollen. No microscopical examination was reported.

In addition to these reports of fatal cases with complete autopsies, there are a considerable number of reports of fatal cases with partial autapsies, and also of cases of mild types of poisoning, some of which are of sufficient interest to reproduce here.

Orfila $^{14}$ collected two cases. In the first case, observed by Desgranges ${ }^{15}$ the fumes were evolved by the breaking of a flask of nitric acid, exposure lasting for about five minutes. The patient then went into the open air and recovered from the sensation of choking. He was very thirsty about four hours later, and twelve hours after exposure was seized with coughing and prostration, and seventeen hours after the accident had an attack of intense dyspnea with cyanosis, pain in the abdomen, convulsive movements, and delirium, and died about twentyseven hours after the inhalation of the gas. There was no autopsy.

In the second case, ${ }^{13}$ a healthy man of 22 years inhaled a large amount of fumes set free on the breaking of a flask of nitric acid. Some hours afterward he took a walk in order to relieve a sensation of oppression in the chest. About nine hours after the accident intense dyspnea supervened. Forty-eight hours

13. Kockel: Vrtljschr. f. gerichtl. Med., 1898, xv, 1.

14. Orfila: Toxicologie, Trans. by Kühn, Leipsic 1839, i, 124 .

15. Desgranges: Jour. de méd., continué, 1804, viii, 487.

16. Cherrier: Bull. Soc. méd. émul., 1823. 
after the gas was inhaled the patient died with typical symptoms. At autopsy the right lung was found to fill the entire half of the thorax; it was solid and edematous, most of the fluid appearing to be dark fluid blood. In the left lung there were large amounts of bloody fluid but some of the parenchyma was still well aerated. The mucous membrane of the trachea and bronchi was of a blood-red color. There were superficial ulcerations in the cardia and pylorus. The contents of the stomach were sour. The other organs showed no changes.

In a third case, ${ }^{17}$ a powerful man, 34 years old, was cleaning copper with nitric acid. After two days, during which time he had inhaled a considerable amount of the fumes of the acid, he was seized with headache, cough and oppression in the chest. Twenty-four hours later on examination he was found to have intense dyspnea, protruding eyes, purple lips, and frequent cough, with sticky, yellow sputum. There were coarse râles over the chest. He died twenty: four hours after the onset of the symptoms. At autopsy the lungs were very voluminous, crepitant and of normal color. The mucous membrane of the trachea and bronchi was vivid red and much swollen. The bronchi contained much yellow fluid and a similar fluid could be expressed from the lung tissur on section.

Manouvriez ${ }^{18}$ reported several cases, the exposure occurring when a warehouse containing sodium nitrate and other substances caught fire. One of the workmen made several attempts to remove the sacks and was exposed for a few minutes each time to the vapors of nitrogen tetroxid. After the third attempt he collapsed and was taken to his home. He complained of thirst and intense dyspnea with intense pain in the chest, and died about four hours after the exposure. His assistant died with the same symptoms about eight hours after the exposure. Another exposed person suffered from violent vomiting and diarrhea, but was ill for only two days.

Autopsies on the first two cases showed that the blood was black and acid to litmus paper, the latter seeming a rather remarkable condition in the light of our presert knowledge of the great acid-neutralizing capacity of the blood and the fact that a change in reaction was not noted in any of the animal experiments which follow. There was intense congestion of the bronchi and lungs which were distended with blood and contained several areas of hemorrhage. Hyperemia of the mucous membrane of the stomach was noted, with congestion of the other organs.

Künne ${ }^{13}$ reported briefly eleven cases of intoxication due to the inhalation for only two or three minutes of fumes arising during a fire in a building in which a large number of carboys of nitric acid were stored. In some of the cases no symptoms appeared until six or eight hours afterward; the patients having stood about watching the.fire, smoking their pipes, etc., and finally going home to wed and to sleep. They were wakened by intense dyspnea. Some of the patients vomited, and showed great cyanosis, nervous symptoms, and rapid and fatal heart action. There were two fatal cases, but these were not observed by Künne. Seven of the patients ran a mild course and were discharged nine days after the exposure as cured. Four others were much more scriously affected and were not able to return to work for two weeks after the exposure. The only exceptional point was that three of the patients showed albumin in the urine. All the others had the usual symptoms previously described.

Pearse ${ }^{20}$ reported the case of a man, 35 years of age, who inhaled the fumes of nitrogen tetroxid on the breaking of a carboy of nitric acid. Six hours after the inhalation the patient had pains in the chest and difficulty in swallowing and talking. Eight and a half hours after inhaling the fumes he had an attack of

17. Sucquet: Details are given by Chevallier and de Loury, Ann. d'hyg., 1847, xxxviii, 323 .

18. Manouvriez: Bull. de l'acad. de méd., Paris, 1897, xxxvil, series 3, p. 306.

19. Künne: Deutsch. med. Wchnschr., 1897, xxiii, 414.

20. Pearse: Albany Med. Ann., 1899, xx, 28. 
severe dyspnea; respirations, 40; high pitched respiratory murmurs over bronchi and right lung. The left lung was not involved. Bloody mucus was expectorated. Twenty-four hours after the accident signs of consolidation developed in the right lung with edema and cyanosis of the lips. The patient became delirious and died twenty-nine hours after inhaling the fumes, of edema of the lungs.

Wood and Stephen ${ }^{21}$ reported the case of a chemist who broke a bottle containing about three liters of nitric acid, and spent about half an hour in eleaning up the fluid by means of sawdust and cloth; he was not inconvenienced by the fumes. Eight and a half hours after the accident he began to suffer from intense dyspnea and expectorated large quantities of straw-colored fluid, nearly a liter in amount. Respirations, 62; marked cyanosis ard very violent cough on the first day; cough less on the second day; none after the third day. Recovery was slow, the patient remaining in bed for ten days.

Harrington ${ }^{22}$ reported nine cases of poisoning by nitrogen tetroxid fumes following the breaking of a carboy containing nitric acid. None of the patients felt any bad effects until five to eight hours after the exposure, when they developed dyspnea, rapid respiration, cough, and in some cases delirium. There were no fatalities.

Lange $^{23}$ reported two cases of an organizing bronchitis which do not correspond either in the clinical history or in the general autopsy findings with the type of disease due to inhalation of irritating gases and are here quoted merely because they are frequently referred to in the literature of the subject. In the first case there was a history of cough for eight days, chills and headache, the patient entering a hospital and dying on the ninth day of the disease with a pneumonia, showing subpleural hemorrhages and numerous gray miliary nodules throughout the lung tissue, which proved to be fine terminal bronchi. Each small nodule was surrounded by about $1 \mathrm{~mm}$. of dark colored lung tissue. The alveoli lying between these nodules showed no exudation. In the second case, the pationt, 32 years old, had been sick for six months with cough and dyspnea. For four weeks before death he had great discomfort so that he was not able to work. Autopsy showed voluminous lungs, hemorrhagic spots in the pleura, and on the cut surface large numbers of small nodules which looked like miliary tubercles. These grayish nodules were surrounded by a narrow ring of reddish tissue. The lung between these areas was quite normal. The vessels showed no thrombi.

Pott ${ }^{26}$ reported an instance in which nitrogen tetroxid fumes were formed by the action of acid phosphate on sodium nitrate, the mixture being a preparation used as a fertilizer. About thirty persons were exposed to the vapors, of whom two died, one in twelve hours and one in forty hours. There was no autopsy in either case. The symptoms were typical as described above. Eight persons were confined to bed for a number of days with very severe dypsnea and cough, the sputum being thick and yellow and containing blood and alveolar epithelium. In the most serious case the patient was confined to bed for eight days, but recovery was complete.

Hall and Cooper ${ }^{25}$ reported a case in which a carboy of nitric acid was accidentally broken and the acid spread over the floor, attacking some zinc plates and sawdust and starting a fire. Twenty people were seriously affected, four of whom died, two on the second day and two several weeks later. Dyspnea was present in 100 per cent. of the cases, cough in 93 per cent., vomiting in 53 per cent. Cough with bloody expectoration persisted in 27 per cent. The patients who recovered were found to be more susceptible to cold than before. Two cases were autopsied. The records are very incomplete; it is stated that in one the lungs were large and voluminous and the bronchi filled with bloody

21. Wood and Stephen: Australasian Med. Gaz., 1909, xxviii, 25.

22. Harrington: Wisconsin Med. Jour., 1903, i, 177.

23. Lange: Deutsch. Arch. f. klin. Med., 1901, Ixx, 342.

24. Pott: Deutsch. med. Wchnschr., 1884, x, 451 .

25. Hall and Cooper: Jour. Am. Med. Assn., 1905, xlv, 396. 
fluid. There was much edema of the lung tissue and a thickening of the bronchial mucosa. The second case in which death occurred one month after exposure showed bronchopneumonia with consolidation of the lung, and microscopically the alveoli were filled with cells and beginning fibrosis.

Bauer $^{26}$ reported a case of an anilin factory worker who inhaled nitrogen tetroxid. After a short time he had dyspnea and cough, and he died in two days with pulmonary edema. An autopsy showed acute bronchitis, Iobular pneumonia and edema, with thrombi in the pulmonary vessels.

\section{ANIMAL EXPERIMENTS}

In order to study further the lesions seen in the reported case, a series of experiments were carried out on dogs.

Among those who had made previous studies of acid poisoning on animals may be mentioned Lesser, ${ }^{27}$ who exposed rabbits and dogs to the vapors given off on warming nitric acid. He showed that only occasionally bronchitis, bronchopneumonia, or edema of the lungs supervened. Even after exposing dogs for weeks to acid vapors he was not able to find any microscopical changes in the lungs. The reason for this is that the acid volatilizes unchanged and condenses in the nasal passages, and while it may corrode the tissues there does not penetrate further. Practically no nitrogen tetroxid is given off from ordinary nitric acid on warming.

Kockel, Bauer, ${ }^{26}$ Gréhant and Quinquaud, ${ }^{28}$ and Eulenberg ${ }^{29}$ carried out animal experiments with nitrogen tetroxid. Those of Gréhant and Quinquaud and Eulenberg are not important here because the animals either died within a few minutes or recovered from the inhalation, and no microscopical examinations were made.

Kockel's animal experiments gave the following results: $:^{13}$ The blood of the animals dying in an atmosphere of nitrogen tetroxid fumes had a chocolate-brown color, but when the animals had a chance to breathe fresh air for a few minutes after inhalation of the gas, the blood was merely dark in color and not otherwise abnormal. The lungs were usually markedly emphysematous; the color was almost always bright red; and on section there were usually reddish areas and much edema. Extensive hepatization was noted only in the animals killed four or five days after the exposure to the fumes. The mucous membrane of the respiratory passages was congested and edematous. The spleen and kidneys showed no gross lesions. The liver was occasionally intensely congested. In some animals swelling, edema and ulceration of the mucous membrane of the stomach and intestine was observed. Microscopically, the chief lesion in the lungs was intense hyperemia with

26. Baver: Original report not accessible. Few details given. Abstract in Virchow-Hirsch, Jahresb., 1895 , p. 460.

27. Lesser: Ztschr. f. physiol. Chem., 1877, i, 165.

28. Grehant and Quinquaud: Compt. rend. Soc. de biol., 1884, viii, t.i, 469.

29. Eulenberg: Vrtljschr. f. gerichtl. Med., 1876, xxv, 209. 
hyaline thrombi in the capillaries, a condition also observed by Bauer. Thrombi also were found in the larger vessels leading to the lungs in some cases. An extensive edema of the lung tissue involving the perivascular and peribronchial connective tissue and also the alveolar walls was quite common. Over areas of moderate extent in the lungs the alveoli contained serous or fibrinous exudate. In the animals which survived for a number of days there was almost always a bronchopneumonia, the alveoli being filled with red and white cells and desquamated epithelium. Four or five days after the inhalation a considerable pneumonic infiltration was usually present, the alveoli being filled with desquamated epithelium, which not infrequently fused to syncytial-like masses. The parts of the lungs free from edema and exudate were emphysematous. Plugs of epithelium and leukocytes cemented with mucus often filled the smaller bronchi. Multiple focal necroses were occasionally present in the liver.

Spectroscopical examination of the blood showed that the chocolatebrown color observed in the animals dying in an atmosphere of nitrogen tetroxid fumes was due to the formation of hematin. This substance was also observed by Kobert in the urine of a patient, but is not as a rule demonstrable in those patients who have survived exposure to the gases. Probably only very small amounts of this substance are formed in the blood. No morphological changes in the circulating blood were noted.

The necroses occasionally observed in the mucous membrane of the stomach and intestine were undoubtedly due to the fact that some of the fumes had dissolved in the saliva and been swallowed, causing erosions. The results of the animal experiments, therefore, correspond quite closely with the lesions found in human beings.

My own experiments confirm and extend Kockel's results. A few characteristic protocols are appended. Dogs were selected for the experiments because of the ease with which pneumonia is induced in these animals and because the lungs are voluminous enough to permit of considerable topographical variation in the pneumonic areas.

Dog 1.-Large, powerful animal weighing about $15 \mathrm{kilos}$; was anesthetized with ether and allowed to fill his lungs four times with fumes of nitrogen tetroxid mixed with about an equal volume of air. The animal revived from the ether and seemed pretty well for some hours, but on the following morning was suffering from severe dyspnea both inspiratory and expiratory. He remained quietly in his cage and refused to eat. He coughed a good deal, and forty-eight hours later was killed. The lungs showed an acute bronchitis with edema, desquamation of the bronchial epithelium, and a small amount of lobular pneumonia, the alveoli containing large cells, many of them pigmented, and a good deal of fibrin and a few leukocytes. The remainder of the lung was deeply congested and showed a good deal of edema with a marked emphysema especially in the anterior portions. The other organs showed no lesions. Cultures from the lungs were sterile. The condition corresponds to that noted in persons dying soon after inhaling the gas. 
Dog 3.-Terrier, weighing about 10 kilos, was lightly chloroformed and allowed to fill his lungs about twelve times with a mixture of equal volumes of air and nitrogen tetroxid. The animal died about ten minutes later and on removal the lungs were found to be almost solid with edematous bloody fluid. Microscopically the alveoli were filled with a serous edema containing many red cells. No lesions were present in the other organs. A similar condition has been noted in some of the rapidly fatal human cases.

Dog 4.-Terrier, weighing about $9 \mathrm{kilos}$, was lightly chloroformed and allowed to fill his lungs three times with a dilute mixture of air and nitrogen tetroxid. It soon recovered lut refused to eat, had a good deal of difficulty in breathing, with coarse râles over the chest, and coughed a good deal, raising yellowish frothy mucoid sputum. The animal was killed after five days. The lungs showed extreme emphysema with a scattered lobular pneumonia (Fig. 2) most marked in dependent portions. The bronchi were congested and filled with mucus. There were no other macroscopic lesions. Microscopically the Iungs showed extensive lesions; the other organs were normal except for a few focal necroses in the liver. The bronchial mucosa was extremely edematous and congested, but the epithelium was still intact (Fig. 10), the cilia even being present in a few areas. The epithelium of the terminal bronchi was swollen and desquamated (Fig. 11), as was that of the alveoli (Fig. 12). The alveolar walls were thickened and edematous, and the capillaries congested. Emphysematous areas alternated with patches of pneumonia (Fig. 2). There were plugs of epithelium in the terminal bronchi (Fig. 13), some of them composed wholly of cells, others of cells covering a growth of îbrous tissue. This is the lesion described by Fraenkel as "bronchiolitis fibrosa obliterans." Similar plugs filled some of the alveoli (Fig. 14), others contained solid masses of desquamated cells, others were filled with blood, fibrin and coagulated serum; still others were lined with unregenerating epithejium. Mitotic figures were rare, though present. A number of the smaller vessels showed thrombi in various stages of organization (Fig 15.). The lesions in the lungs were very irregularly distributed and corresponded very closely in all details with those of the case of $D$, here reported, except perhaps in the extent of the emphysema, this lesion being less marked in the dog than in the human material, while the bronchiectasis was more extensive in the animal.

Dog 5.-Irish terrier, weighing $7 \mathrm{kilos}$, was etherized and given ten breaths of very dilute nitrogen tetroxid. Nineteen days later the dog still had a cough but otherwise seemed well. It was then given four deep breaths of dilute nitrogen tetroxid, and eighteen days later three inhalations of the same. Six weeks later it was killed. The lungs seemed normal in the gross, and microscopically it could not be determined that there were any changes; possibly the lungs were slightly more emphysematous than those of a normal dog, but repair was extraordinarily complete.

Dog 6.-Fox terrier, weighing about 9.5 kilos, was given, under ether anesthesia, six breaths of dilute nitrogen tetroxid and air mixture. The following day the dog was very quiet, did not seem to suffer very much pain, but coughed a good deal and showed intense dyspnea. The second day after he coughed up thin, foamy sputum, did not eat, and vomited small quantities of mucus; for six days he coughed continuously and was then killed. On opening the thorax the lungs were found to be covered with a thin layer of fresh fibrin which was especially abundant over patchy areas of deep congestion. These congested areas were scattered irregularly throughout, and were especially abundant near the thin edges of the lobes; they were quite firm to pressure. The remainder of the lung was well aerated. The bronchi were filled with thick mucus; the mucous membrane was congested. The bronchial lymph-nodes were not enlarged. The kidneys and other organs appeared normal. The brain showed no hemorrhages nor softening. Microscopically the lungs showed irregular areas of lobular pneumonia with fibrin, a few leukocytes, and many desquamated alveolar epithelial cells. There was considerable fusion of the alveoli to form large open spaces. 
The alveolar walls were much thickened and congested. There was beginning repair of the epithelium in some of the alveoli. The kidneys and liver showed no microscopical changes. Cultures from the lung were sterile.

Dog 7.-Short-haired, female terrier, weighing 9.4 kilos, while under morphin was given three deep breaths of the concentrated gas. The animal was very dyspneic for a few minutes and then became active and apparently suffered no discomfort. Six days afterward it was coughing a good deal. One month later it was apparently entirely well and healtly, and was then put under the influence of morphin and given two exposures to nitrogen tetroxid fumes, about two hours apart. The day following the animal appeared very sick and refused to eat or drink. Râles in throat and difficult breathing. Two days later it was still ccughing up a white mucous sputum. The animal was very quiet and refused to eat. Five days later it was killed. The lungs were very voluminous. There were firm sunken areas along the borders of the posterior portions of the lobes. These areas were of a grayish color. The bronchi protruded from the surface of the cut lung and contained a mucopurulent fluid. The solid lung tissue was greenish-gray in color. The bronchi in some portions of the lung were very much dilated. The microscopic changes in the lungs were about the same as in Dog 4, but there was much more emphysema and the bronchi were more extensively altered and dilated. The second exposure evidently extended these changes in an already diseased lung.

Dog 13.- Short-haired terrier, weighing $8.5 \mathrm{kilos}$. Under morphin the animal was given several deep breaths of well diluted nitrogen tetroxid. It recovered and at the end of a month was apparently well, but finally began to cough and lose weight, and was killed tive weeks after exposure. During the last few days the animal coughed a good deal. At autopsy a lobular bronchopneumonia was found together with the usual emphysema. An atypical pneumococcus was isolated from the pneumonic areas, and the lesion, when examined microscopically, was found to be quite different from that seen in the other dogs, corresponding to that found after bacterial infections. The alveoli were filled with a richly leukocytic exudate, and bacteria could be demonstrated by appropriate stains. The lesion was evidently a spontaneous bacterial pneumonia developing in a lung weakened by the action of the nitrogen tetroxid fumes. Such a pneumonia is not infrequent in animals on whom severe operations have been performed.

\section{PROPHYLAXIS}

The chief danger of nitrogen tetroxid lies in the fact that a 1 per cent. mixture of the gas with air can be inhaled without inducing coughing or spasm of the larynx, so that the bronchial and pulmonary epithelium is seriously damaged before severe symptoms supervene. This is quite impossible with chlorin, sulphur dioxid, or ammonia, which cannot be inhaled even in a mixture much diluted with air without causing a spasm of the glottis and suffocation.

As the gas is generated by contact of nitric acid with any organic matter, the straw packing and wooden cases in which the acid carboys are inclosed usually start the reaction, the heat evolved often being sufficient to set the woodwork on fire, thus increasing the difficulty of handling the situation. Nitric acid should, therefore, be stored in an amply ventilated separate building with stone or concrete floor, if possible, and arrangements should be made so that the room can be promptly flooded with water. The handling of the carboys should be 
placed in the hands of a few skilled workmen who have been instructed as to the dangers of inhaling the fumes arising when the acid is spilled. Sand is the best material for absorbing any acid which may be upset. If it is necessary for the workmen to enter a room in which the acid has been spilled, their mouths and noses should be covered with cloth moistened with very dilute ammonia.

\section{TREATMENT}

There is no satisfactory treatment after the gas has been inhaled. Breathing ammonia vapor has been suggested, but this only adds a second corrosive gas to that already present in the lungs. Oxygen inhalations aid in combating the dyspnea, but do not touch the cause of this symptom, which is chiefly due to the edema of the walls of the bronchi. Morphin and stimulants should be given according to the symptoms.

\section{CONCLUSIONS}

1. The inhalation of even small quantities of nitrogen tetroxid gives rise to an exceedingly dangerous pulmonary condition with a characteristic lung lesion both in man and in animals.

2. As there is no satisfactory treatment of the condition it is of the utmost importance that careful instruction be given to all factory laborers or laboratory workers who have to handle concentrated nitric acid as to the dangers incurred and the means of avoiding them.

\section{BIBLIOGRAPHY}

An excellent description of the symptoms in poisoning by nitrogen tetroxid with a fair bibliography is to be found in Kunkel: Handbuch der Toxikologie, Jena, 1901, p. 282. Pott (loc. cit., note 24) gives references to the older cases. Kobert: Lehrbuch d. Intoxikation, 1906, also gives a considerable number of references to the literature, not without the usual inaccuracies. Kockel (loc. cit., note 13) refers to a number of recent cases, and Schubert (loc. cit., note 7 ) has a fair bibliograplyy and gives important suggestions for prophylaxis. The best bibliography is contained in Witthus and Becker: Medical Jurisprudence and Toxicology, 1911, iv, 301, New York. 